\title{
ARTICLE Deletion of the type 2 metabotropic glutamate receptor increases heroin abuse vulnerability in transgenic rats
}

\author{
Jun-Tao Gao ${ }^{1,2}$, Chloe J. Jordan $\mathbb{D}^{1}$, Guo-Hua Bi ${ }^{1}$, Yi He ${ }^{1}$, Hong-Ju Yang ${ }^{1}$, Eliot L. Gardner ${ }^{1}$ and Zheng-Xiong Xi (iD)
}

Opioid abuse is a rapidly growing public health crisis in the USA. Despite extensive research in the past decades, little is known about the etiology of opioid addiction or the neurobiological risk factors that increase vulnerability to opioid use and abuse. Recent studies suggest that the type 2 metabotropic glutamate receptor (mGluR2) is critically involved in substance abuse and addiction. In the present study, we evaluated whether low-mGluR2 expression may represent a risk factor for the development of opioid abuse and addiction using transgenic mGluR2-knockout (mGluR2-KO) rats. Compared to wild-type controls, mGluR2-KO rats exhibited higher nucleus accumbens (NAC) dopamine (DA) and locomotor responses to heroin, higher heroin self-administration and heroin intake, more potent morphine-induced analgesia and more severe naloxone-precipitated withdrawal symptoms. In contrast, mGluR2-KO rats displayed lower motivation for heroin self-administration under high price progressive-ratio (PR) reinforcement conditions. Taken together, these findings suggest that mGluR2 may play an inhibitory role in opioid action, such that deletion of this receptor results in an increase in brain DA responses to heroin and in acute opioid reward and analgesia. LowmGluR2 expression in the brain may therefore be a risk factor for the initial development of opioid abuse and addiction.

Neuropsychopharmacology (2018) 43:2615-2626; https://doi.org/10.1038/s41386-018-0231-5

\section{INTRODUCTION}

Opioid abuse is a rapidly growing public health problem. Nearly 13.5 million people worldwide use opioids [1]. In the US alone, more than 100 people died each day in 2016 from an opioidrelated overdose, and over two million were diagnosed with an opioid use disorder [2]. Opioid use disorder is characterized by unsuccessful attempts to reduce opioid use despite negative consequences, excessive time spent using or procuring opioids, the development of tolerance (i.e., increasing amounts of drug are needed to achieve desired effects), and the experience of withdrawal syndrome during cessation of use [3]. Although millions of individuals use opioids every year, approximately $23 \%$ of heroin users develop opioid addiction [4], suggesting preexisting risk factors may convey vulnerability to opioid use disorder. Preventative measures can be effective in reducing the prevalence of opioid addiction, but require an understanding of risk factors such that targeted interventions can be efficiently implemented in vulnerable individuals [5]. Despite extensive research on the etiology and development of opioid addiction, relatively little is known about neurobiological risk factors that can be used to identify vulnerability to the transition from opioid use to abuse and dependence.

Electrophysiological studies suggest that opioid reward or reinforcement could be mediated by activation of mu-opioid receptors on GABAergic neurons or GABAergic afferents in the ventral tegmental area (VTA), which causes dopaminergic (DA) neuron disinhibition or activation in this region $[6,7]$. Since DA plays an essential role in drug reward [8], most of the studies regarding the etiology and pathophysiology of the development of drug abuse and addiction have focused on individual differences in the mesocorticolimbic DA system [9].

In addition to DA, glutamate plays an important role in substance use disorders [10]. For example, accumulating evidence suggests that cocaine- and heroin-induced relapse to drug seeking is closely associated with increased DA and glutamate in the nucleus accumbens (NAc) [11, 12]. In particular, metabotropic glutamate receptors may represent viable treatment targets for addictions due to their relatively regional distributions and their modulatory role in synaptic neurotransmission, in contrast to ionotropic glutamate receptors that are expressed ubiquitously throughout the central nervous system. Metabotropic glutamate receptors are divided into three groups: Group 1 includes GGluR $_{1}$ and $\mathrm{mGluR}_{5}$; Group 2 includes $\mathrm{mGluR}_{2}$, and $\mathrm{mGluR}_{3}$; and Group 3 includes $\mathrm{mGluR}_{4}, 6-8$ [13]. Of these, $\mathrm{mGluR}_{2 / 3}$ are located predominantly on presynaptic glutamate terminals and are Gai/ o-coupled, such that they function largely as autoreceptors to suppress glutamate release $[11,13]$. As such, $\mathrm{mGluR}_{2 / 3}$ receptors may be attractive therapeutic targets for substance use disorders. mGluR $_{2 / 3}$ agonizts reduce DA and glutamate release in the NAc [14] and inhibit cocaine, nicotine, or alcohol self-administration [11]. While $\mathrm{mGluR}_{2 / 3}$ agonizts do not alter heroin selfadministration [15], they do significantly inhibit morphineinduced conditioned place preferences [16], and reinstatement to morphine place conditioning [17] or cue-induced reinstatement to heroin seeking $[18,19]$. In addition, $\mathrm{mGluR}_{2 / 3}$ are involved in pain and opioid withdrawal $[20,21]$. The $\mathrm{mGluR}_{2 / 3}$ agonist, LY379268, potentiates morphine analgesia while reducing morphine tolerance [22] and opioid withdrawal-induced synaptic

\footnotetext{
${ }^{1}$ Addiction Biology Unit, Molecular Targets and Medications Discovery Branch, National Institute on Drug Abuse, Intramural Research Program, Baltimore, MD 21224, USA and ${ }^{2}$ Department of Physiology, Jilin Medical University, Jilin 132013, P.R. China

Correspondence: Z.-X. Xi (zxi@mail.nih.gov)

These authors are contributed equally: Jun-Tao Gao, Chloe J. Jordan
}

Received: 8 June 2018 Revised: 20 September 2018 Accepted: 21 September 2018

Published online: 3 October 2018 
plasticity [23]. In contrast, LY341495, an $\mathrm{mGluR}_{2 / 3}$ antagonist, exacerbates naloxone-precipitated morphine withdrawal [24]. These findings suggest that $\mathrm{mGluR}_{2 / 3}$ may participate in multiple aspects of opioid addiction. However, to our knowledge little is known as to whether altered $\mathrm{mGluR}_{2 / 3}$ expression and function represents an a priori risk factor for the development of opioid abuse and addiction.

To begin elucidating whether reduced mGluR2 expression conveys vulnerability to drug abuse, we have recently used transgenic approaches to selectively delete mGluR2 in rats. We found that deletion of mGluR2 escalated cocaine self-administration, suggesting that mGluR2 loss could be a risk factor for cocaine abuse [25]. However, it is unknown whether this finding extends to more widely abused drugs with different mechanisms of action, such as opioids. In the present study, we evaluated whether deletion of mGluR2 in rats alters multidimensional aspects of opioid addiction, including NAC DA or glutamate responses to heroin, heroin sensitization, opioid reward, relapse, analgesia and tolerance, as well as naloxone-precipitated withdrawal symptoms in both wild-type (WT) and mGluR2-KO rats.

\section{MATERIALS AND METHODS}

Animals

Male WT and mGluR2-KO rats with Wistar strain genetic background $(250-300 \mathrm{~g})$ were bred at the National Institute on Drug Abuse (NIDA) from three mGluR2 ${ }^{+/-}$breeding pairs purchased from Transposagen Biopharmaceutical. They were individually housed in a climate-controlled room on a reverse light-dark cycle with ad libitum access to food and water. Genotyping was performed by Charles River Laboratories. Rats were housed individually in a climate-controlled animal colony room on a reversed light-dark cycle with ad libitum access to food and water. All experimental procedures were conducted in accordance with the National Research Council's Guide for the Care and Use of Laboratory Animals and were approved by the National Institute on Drug Abuse's Animal Care and Use Committee.

\section{Drugs}

Morphine sulfate and heroin were provided by the NIDA drug supply program. Naloxone hydrochloride was purchased from Enzo Life Sciences (Farmingdale, NY, USA). All drugs were dissolved into $0.9 \% \mathrm{NaCl}$. Biphenylindanone A (BINA), the positive-allosteric mGluR2 modulator, was purchased from the Tocris Bio-Techne Corporation (Minneapolis, USA) and dissolved in artificial cerebral spinal fluid for intracranial perfusion during microdialysis.

\section{In vivo microdialysis}

The intracranial guide cannula implantation surgery and microdialysis procedures are the same as we reported previously [25]. Briefly, two guide cannulae (CMA Microdialysis AB, Solna, Sweden) were implanted into NAc (AP +1.7; $\mathrm{ML} \pm 1.7 ; \mathrm{DV}-5.8 \mathrm{~mm}$ with $6^{\circ}$ angled away from the midline) for in vivo brain microdialysis. After 7 days of recovery from surgery, a probe was inserted into the NAC $12 \mathrm{~h}$ before experiments began. On the experimental day, dialysis buffer was perfused through the probe $(2.0 \mu \mathrm{L} / \mathrm{min})$ via a syringe pump. To prevent DA degradation, dialysis samples were collected every 20 min into $10 \mu \mathrm{L}$ of $0.1 \mathrm{M}$ perchloric acid. After $2 \mathrm{~h}$ of baseline collection, animals received either vehicle, increasing concentrations of BINA $(0.01-100 \mu \mathrm{m})$ perfused locally into the $\mathrm{NAC}$, or two systemic doses of heroin $(0.25$ and $1.0 \mathrm{mg} / \mathrm{kg}, \mathrm{s.c}$.$) .$ After collection, all samples were frozen at $-80^{\circ} \mathrm{C}$ until analysis. Dialysate DA and glutamate were measured using high-pressure liquid chromatography with electrochemical and fluorometric detection, as reported previously [26]. After microdialysis experiments, rats were anesthetized with a high dose of pentobarbital $(>100 \mathrm{mg} / \mathrm{kg}$ i.p.) and perfused transcardially with $0.9 \%$ saline followed by $10 \%$ formalin. Brains were removed and placed in $10 \%$ formalin for histological verification of microdialysis probe locations.

Heroin-induced locomotor activity

Before heroin administration, each animal was placed into a locomotor detection chamber (Accuscan Instruments) for 3 days ( $4 \mathrm{~h}$ per day) for environmental habituation. WT and mGluR2-KO rats were then treated with saline $(0.5 \mathrm{mg}$, i.p.) for 3 days followed by heroin ( $1.0 \mathrm{mg} / \mathrm{kg}$ i.p.) for 7 days. Each day, rats were placed in the chamber for $1 \mathrm{~h}$ of habituation, then removed and given either saline or heroin, and locomotor activity was recorded for two additional hours. Seven days after the last heroin injection rats were challenged again with the same heroin dose prior to being placed back into the locomotor chambers for $2 \mathrm{~h}$. Data were collected in 10-min intervals each day using the VersaMax data analysis system (Accuscan Instruments, Inc., Columbus, OH, USA). Distance traveled (cm) was used to compare basal and heroin-enhanced locomotion in WT and mGluR2-KO rats.

Intravenous heroin self-administration

Surgical i.v. catheter implantation and heroin self-administration procedures were identical to those reported previously [25]. After 5-7 days of recovery from surgery, each rat was placed into a standard operant chamber and allowed to lever-press for i.v. heroin $(0.1 \mathrm{mg} / \mathrm{kg} /$ infusion) under a fixed-ratio 1 (FR1) reinforcement schedule. Each session lasted $3 \mathrm{~h}$. To prevent heroin overdose, we set a maximal number of 50 infusions. After 5 days of self-administration, the heroin dose was changed from $0.1 \mathrm{mg} /$ $\mathrm{kg} /$ infusion to $0.05 \mathrm{mg} / \mathrm{kg} /$ infusion. Five days after the dose reduction, reinforcement schedules were increased from FR1 to FR2 to promote higher levels of operant responding for heroin. Training continued until stable self-administration was achieved, defined as (i) at least 20 infusions per 3-h session, (ii) less than $20 \%$ variability in daily heroin infusions across two consecutive sessions, and (iii) an active/inactive lever-press ratio exceeding $2: 1$. The total number of active and inactive lever presses and heroin infusions earned were compared in WT and mGluR2-KO rats. The animals were then divided into three groups for subsequent experiments.

\section{Multiple-dose heroin self-administration}

To assess the reinforcing efficacy of heroin, we evaluated selfadministration of multiple heroin doses $(0.00625,0.0125,0.025$, 0.05 , and 0.1 ) in a randomized counterbalanced dose-assignment design. The infusion volumes and durations of each test session were identical except for differing heroin concentrations for each unit dose. Testing continued until stable heroin-maintained responding was achieved. Active and inactive lever presses and heroin infusions were compared in WT and mGluR2-KO rats.

Heroin self-administration under a progressive-ratio reinforcement schedule

To further determine whether mGluR2 deletion alters the motivation to work for heroin reward, we switched an additional group of WT $(n=6)$ and mGluR2-KO $(n=6)$ rats to a progressiveratio (PR) reinforcement schedule following initial heroin selfadministration training [27]. The methods for heroin selfadministration under PR reinforcement were as reported previously [28]. Animals were initially trained for heroin $(0.05 \mathrm{mg} / \mathrm{kg})$ self-administration under FR1 reinforcement schedule for 2 weeks, and then switched to heroin $(0.05 \mathrm{mg} / \mathrm{kg} /$ infusion $)$ selfadministration under PR reinforcement schedule for 5 days, followed by $0.1 \mathrm{mg} / \mathrm{kg} /$ infusion for five additional days. The break point was defined as the maximal work load (i.e., number of active lever presses) completed for the last heroin infusion prior to a 1-h period during which no infusions were obtained by the animal. 
The break points under PR reinforcement were compared between WT and mGluR2-KO rats.

\section{Extinction and reinstatement testing}

After completion of heroin dose-response curves rats underwent response extinction, during which time heroin and the heroinassociated cue light and tone were unavailable, such that lever pressing (without limitation) was recorded, but had no scheduled consequences. Each extinction session lasted for $3 \mathrm{~h}$. Daily sessions continued until responding reached $<15 \%$ of selfadministration levels and varied $<20 \%$ for at least 2 consecutive days. After these extinction criteria were met, each animal received $1 \mathrm{mg} / \mathrm{kg}$ of heroin intraperitoneally (i.p.) to evoke (heroin + cue)-induced reinstatement of drug-seeking behavior. During reinstatement testing, active lever presses lead to reexposure to the cue lights and tones previously paired with heroin infusions, but not to heroin infusions. Active and inactive lever responding for extinction and reinstatement testing were compared in WT and mGluR2-KO rats.

\section{Hot-plate test}

Nociceptive responses to a thermal stimulus was measured in rats using a hot-plate device from IITC Life Science Inc. (Woodland Hills, CA, USA). Briefly, rats were placed on the hot plate $\left(55 \pm 0.4^{\circ} \mathrm{C}\right)$ for a maximum of $60 \mathrm{~s}$, to avoid tissue damage. Pain thresholds were defined as latency to engage in forepaw licking. Baseline pain reflexes were established every $15 \mathrm{~min}$ for $30 \mathrm{~min}$ prior to drug testing, such that a steady latency to forepaw lick was obtained. On test day, the effects of morphine ( 3 and $10 \mathrm{mg} / \mathrm{kg}$, s.c.) on pain reflexes in WT and mGluR2-KO were assessed at 15 or $30 \mathrm{~min}$ intervals for $2.5 \mathrm{~h}$.

\section{Opioid tolerance}

Tolerance to the antinociceptive effects of morphine on the hotplate test in WT vs. mGluR2-KO rats was examined using an 11-day paradigm. On days 1 and 2, rats were injected with saline $(1.0 \mathrm{ml} /$ $\mathrm{kg}$, s.c.) and the hot-plate test was performed to assess baseline pain thresholds. Rats were then treated daily with morphine (10 mg/kg, s.c.) for 9 days, and antinociceptive responses were measured daily at 15 -min interval for $2 \mathrm{~h}$ thereafter. The area under the curve was calculated for each rat each day using the sum of the data during the entire $2 \mathrm{~h}$ sessions, to compare the analgesic effects of morphine between two genotypes of rats.

\section{Naloxone-precipitated morphine withdrawal}

At $3 \mathrm{~h}$ after the last morphine injection in the same groups of rats above, the animals received an injection of naloxone $(3 \mathrm{mg} / \mathrm{kg}$, s.c.) to observe naloxone-precipitated morphine withdrawal symptoms [29]. Morphine dependence was then assessed by examining signs of naloxone-precipitated opioid withdrawal. Briefly, rats were placed in MED Associates open-field activity monitoring systems. Chambers were topped with square plexiglass, and withdrawal signs were observed over $30 \mathrm{~min}$ after the single naloxone injection. Jumping, diarrhea, wet-dog shakes, teeth chattering, digging, erections, body weight loss, and ptosis were counted every $5 \mathrm{~min}$. A global withdrawal score was then calculated by adding averaged withdrawal signs that were weighted for normalization across the different symptoms. Signs were weighted as follows: jumps $\times 0.8$; wet dog shakes $\times 1$; paw tremors $\times 0.35$; diarrhea score $\times 1.5$; teeth chattering score $\times 1.5$ [29]. As a control, saline was given $30 \mathrm{~min}$ before naloxone administration to ensure basal withdrawal signs were minimal.

Data analysis

All data are presented as mean \pm SEM. One-way or two-way ANOVA with repeated measures for time and/or drug dose was used to analyze the difference of the observations between WT and mGluR2-KO rats. Post hoc comparisons between groups were performed using the Student-Newman-Keuls test.

\section{RESULTS}

Validation of mGluR2-KO rats

Figure $1 \mathrm{a}-\mathrm{c}$ shows the structure of the mGluR2 gene and transcript (mRNA) as well as the location of the premature stop codon insertion that causes a nonsense mutation at amino acid C407, deleting the transmembrane and intracellular domains of the receptor and rendering the gene nonfunctional. As shown in representative Western blots in Fig. 1d, this genetic manipulation results in loss of mGluR2, but not $\mathrm{mGluR}_{3}$, in the brain in mGluR2$\mathrm{KO}$ rats. Figure 1e shows that intra-NAc local perfusion of BINA, a the positive mGluR2 allosteric modulator, significantly inhibited NAc glutamate release in WT rats, but not in mGluR2-KO rats in a concentration-dependent manner, when data are expressed as dialysate glutamate concentrations (Fig. 1e, genotype main effect, $F_{1,153}=10.08, p<0.05$; time main effect, $F_{17,153}=0.74, p>0.05$; genotype $\times$ time interaction, $F_{17,126}=0.897, p>0.05$ ) or as percentage of baseline levels (Fig. 1f, genotype main effect, $F_{1,153}=$ $11.68, p<0.01$; time main effect, $F_{17,153}=2.61, p<0.05$; genotype $\times$ time interaction, $F_{17,153}=2.01, p<0.001$ ), suggesting functional loss of mGluR2 in this transgenic rat line.

mGluR2 deletion increases extracellular DA and glutamate responses to heroin

We then examined whether mGluR2 deletion alters neurochemical responses to heroin in WT and mGluR2-KO rats. Figure 2 shows extracellular NAC DA and glutamate before and after heroin injections $(0.25-1.0 \mathrm{mg} / \mathrm{kg}$, i.p.). mGluR2-KO rats exhibited higher baseline levels of extracellular DA compared to WT rats. Two-way ANOVA for repeated measures over 6 baseline samples revealed a genotype main effect (Fig. $2 a, F_{1}, 13=2.28, p<0.01$ ), time main effect $\left(F_{5,65}=1.29, p>0.05\right)$, and genotype $\times$ time interaction $\left(F_{5}\right.$, $65=4.66, p=0.001)$. The mean baseline levels over six samples before heroin injection are $0.125 \pm 0.012 \mathrm{nM}$ in WT rats vs. $0.358 \pm$ $0.006 \mathrm{nM}$ in KO rats (Fig. 2a, $p<0.001$ ). mGluR2-KO rats also showed higher NAC DA responses to heroin both at 0.25 and $1.0 \mathrm{mg} / \mathrm{kg}$ than WT rats (Fig. 2a, genotype main effect, $F_{1,273}=$ $14.9, p<0.01$; time main effect $F_{21}, 273=36.2, p<0.001$; genotype $\times$ time interaction, $\left.F_{1}, 273=7.3, p<0.001\right)$. Due to different baseline levels of extracellular DA, we also compared percentage changes of extracellular DA over baseline immediately before heroin injection. We observed similar statistical results (Fig. 2b, genotype main effect, $F_{1}, 273=1.9, p>0.05$; time main effect $F_{21,273}=36.2, p<0.001$; genotype $\times$ time interaction, $F_{21,273}=2.5$, $p<0.001)$.

We then examined NAc glutamate responses to heroin in the same microdialysate samples. Compared to WT, mGluR2-KO rats also showed higher baseline level of extracellular glutamate. Twoway ANOVA for repeated measures over six baseline samples revealed a genotype main effect (Fig. $2 c, F_{1,14}=12.51, p<0.01$ ), time main effect $\left(F_{5,70}=0.61, p>0.05\right)$, and genotype $\times$ time interaction $\left(F_{5,70}=0.92, p>0.05\right)$. The mean baseline level over six samples before heroin injection are $123.34 \pm 2.98 \mu \mathrm{M}$ in WT rats vs. $198.29 \pm 5.11 \mu \mathrm{M}$ in $\mathrm{KO}$ rats (Fig. $2 c, p<0.001$ ). mGluR2-KO rats also displayed higher NAc glutamate responses to heroin, both at 0.25 and $1.0 \mathrm{mg} / \mathrm{kg}$ (Fig. 2c, genotype main effect, $F_{1,294}=5.2, p<$ 0.05 ; time main effect, $F_{21}, 294=16.6, p<0.001$; genotype $\times$ time interaction, $F_{21,294}=0.86, p>0.05$ ). However, when data were expressed as a percentage of baseline, we observed only a significant time main effect (Fig. $2 d, F_{1}, 294=16.5, p<0.001$ ), but not genotype main effect $\left(F_{1,294}=0.08, p>0.05\right)$ or genotype $\times$ time interaction $\left(F_{21}, 294=0.85, p>0.05\right)$. After the completion of in vivo microdialysis, histological examination indicated that the dialysis probes (membrane portions) were located in the NAC, including both the shell and core (Fig. 2e). 


\section{A (mGluR2 gene structure)}

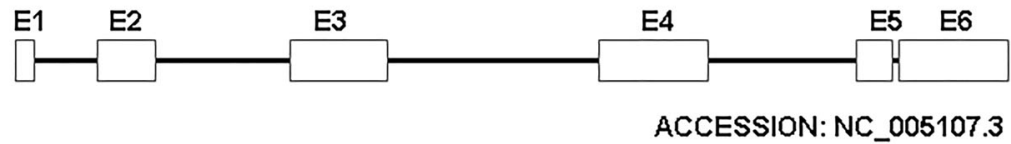

\section{B (mGluR2 mRNA)}

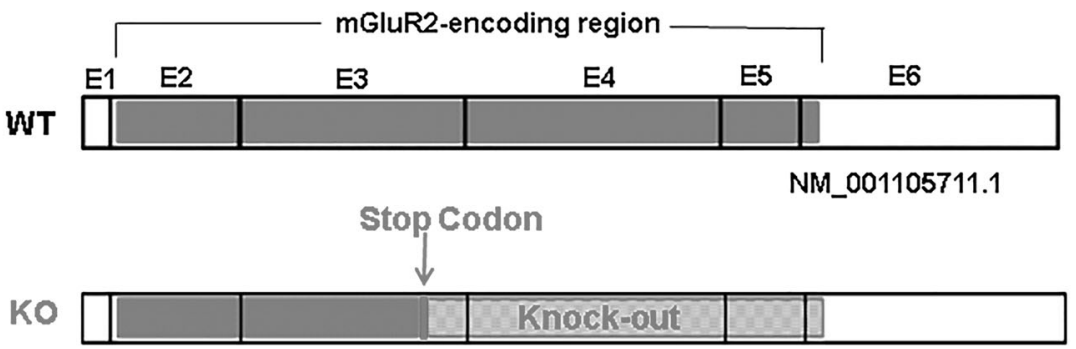

\section{C (mGluR2 receptor structure)}

D (NB)
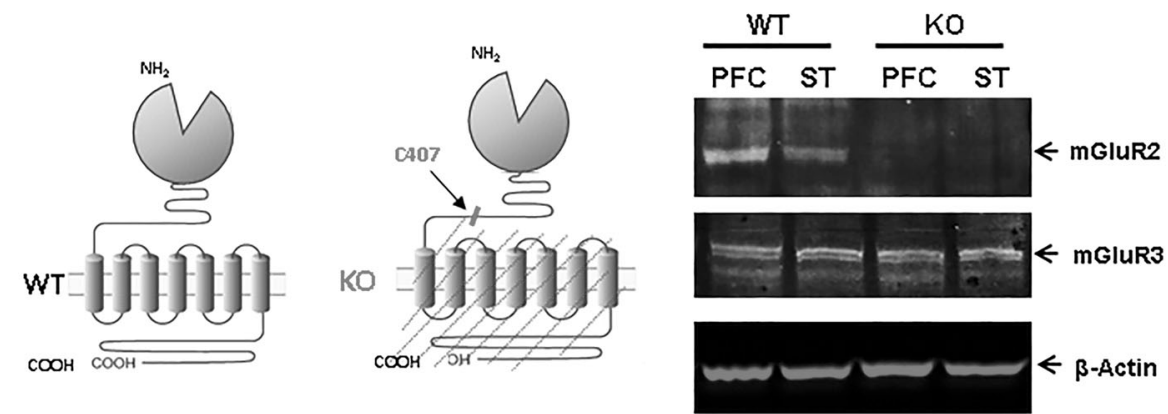

\section{E (Glutamate)}
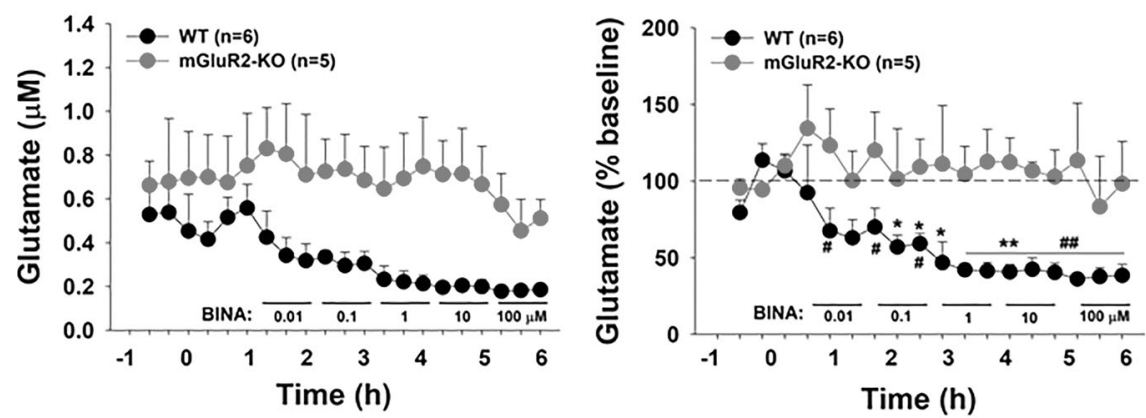

Fig. 1 a Schematic of the mGluR2 gene structure and $\mathbf{b}$ stop codon insertion in KO rats to produce $\mathbf{c}$ a nonfunctional receptor fragment.

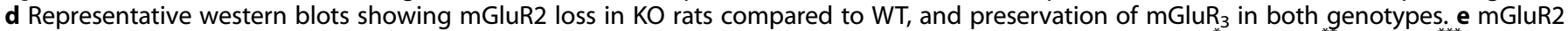
deletion eliminates NAc-induced increases in glutamate by BINA, a positive-allosteric mGluR2 modulator. ${ }^{*} p<0.05,{ }^{* *} p<0.01,{ }^{* * * *} p<0.001$, compared to baseline

mGluR2 deletion increases locomotor sensitization to heroin To determine whether the augmented DA responses to heroin observed in mGluR2-KO rats generalizes to other actions of heroin, we examined the effects of mGluR2 loss on heroinenhanced locomotion over 7 days of heroin treatment. We found that repeated heroin administration progressively enhanced locomotor activity in both strains. However, mGluR2-KO rats displayed higher locomotor responses to heroin than WT rats (Fig. 2f, genotype main effect, $F_{1,120}=1.9, p>0.05$; time main effect, $F_{10,120}=15.2, p<0.001$; genotype $\times$ time interaction, $\left.F_{10}, 120=1.7, p<0.05\right)$. Post hoc individual group comparisons indicated that mGluR2-KO rats exhibited significantly increased locomotor sensitization to heroin compared to WT at multiple timepoints (Fig. 2f).
mGluR2 deletion elevates heroin self-administration behavior We next compared the acquisition and maintenance of heroin self-administration between WT and mGluR2-KO rats (Fig. 3). The majority of WT and mGluR2-KO rats acquired stable i.v. heroin selfadministration after 5-10 days of training. There was no significant difference in the acquisition of heroin self-administration under low-effort (FR1) and high-pay off $(0.1 \mathrm{mg} / \mathrm{kg} /$ infusion) experimental conditions between two groups of rats (Fig. 3a). However, when higher effort (FR2) was required to earn a lower dose of heroin ( $0.05 \mathrm{mg} / \mathrm{kg} /$ infusion), mGluR2-KO rats self-administered more heroin than WT controls (Fig. 3a, genotype main effect, $F_{1}$, ${ }_{108}=9.3, \quad p<0.01$; time main effect, $F_{4,} 108=1.7, p>0.05$; genotype $\times$ time interaction, $F_{4,108}=0.47, p>0.05$ ). Figure $3 b, c$ shows representative heroin self-administration (infusion) records 

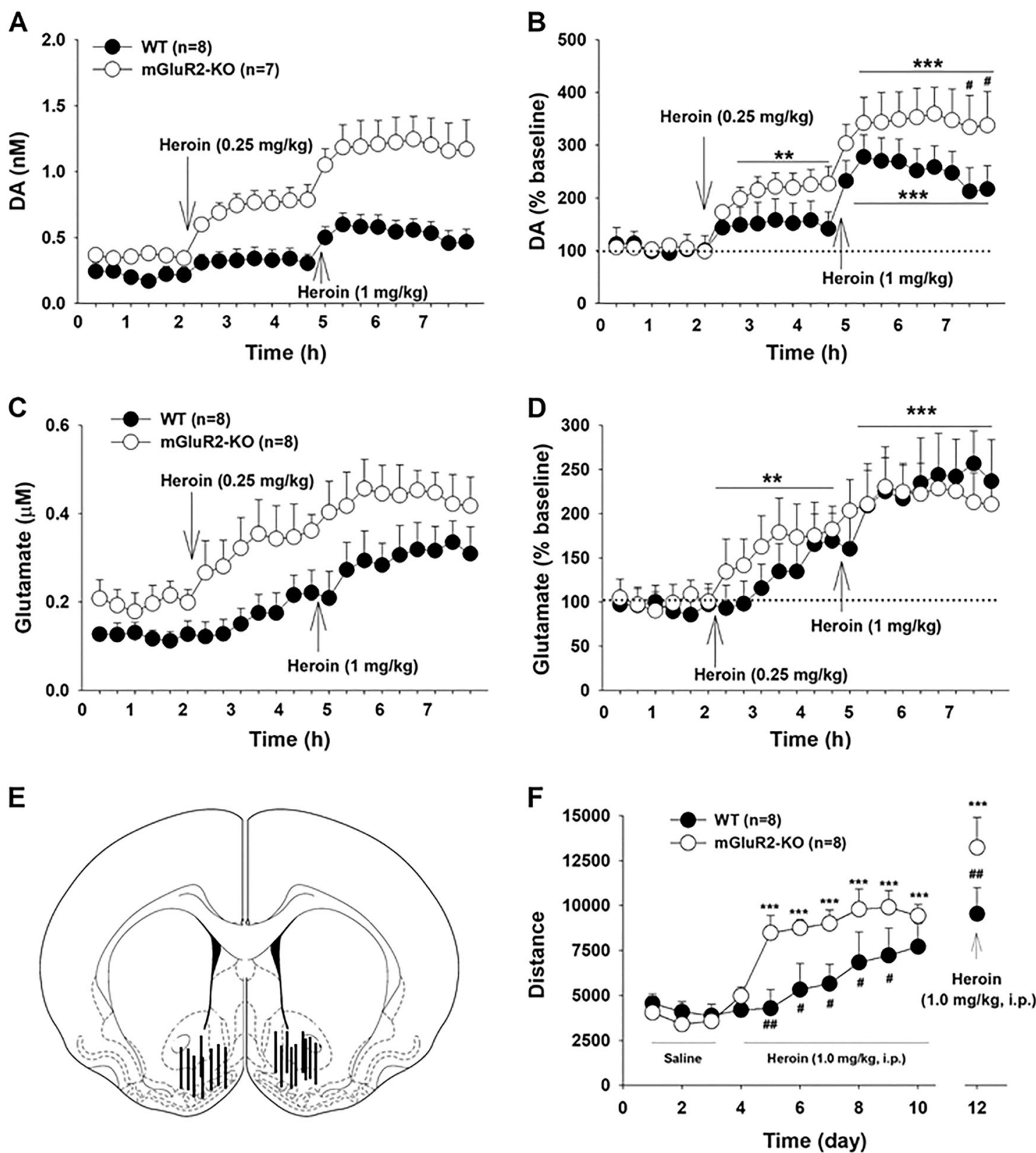

Fig. 2 Heroin-induced changes in extracellular dopamine (DA) and glutamate in the nucleus accumbens of wild-type (WT) and mGluR2-KO rats. a, c Heroin-induced changes in extracellular DA and glutamate, expressed as neurotransmitter concentrations. b, d Changes in extracellular DA and glutamate, expressed as a percentage of preheroin baselines. e Microdialysis probe placements in the nucleus accumbens. f Locomotor responses to heroin (distance traveled) following repeated injections across days. ${ }^{*} p<0.05,{ }^{* *} p<0.01,{ }^{* * *} p<0.001$, compared to baseline/saline. ${ }^{\#} p<0.05,{ }^{\# \#} p<0.01$, compared to WT

from a WT rat and a mGluR2-KO rat, illustrating higher rates of heroin self-administration with shorter interinfusion intervals in mGluR2-KO rats during daily $3 \mathrm{~h}$ sessions under FR2 reinforcement conditions on days 11-15.

We also examined heroin dose-response functions under FR2 reinforcement for lower doses of heroin. Figure 4 a shows typical inverted U-shaped curves of heroin infusions earned across a full range of doses in both WT and mGluR2-KO rats. Consistent with the above findings, mGluR2 deletion caused a significant upward shift in the heroin dose-response curves (Fig. 4a, genotype main effect, $F_{1,56}=9.7, p<0.01$; dose main effect, $F_{4,56}=23.1, p<0.001$; genotype $\times$ dose interaction, $F_{4,56}=0.3$, $p>0.05)$. Post hoc individual group comparisons revealed a significant increase in heroin infusions in mGluR2-KO rats, 


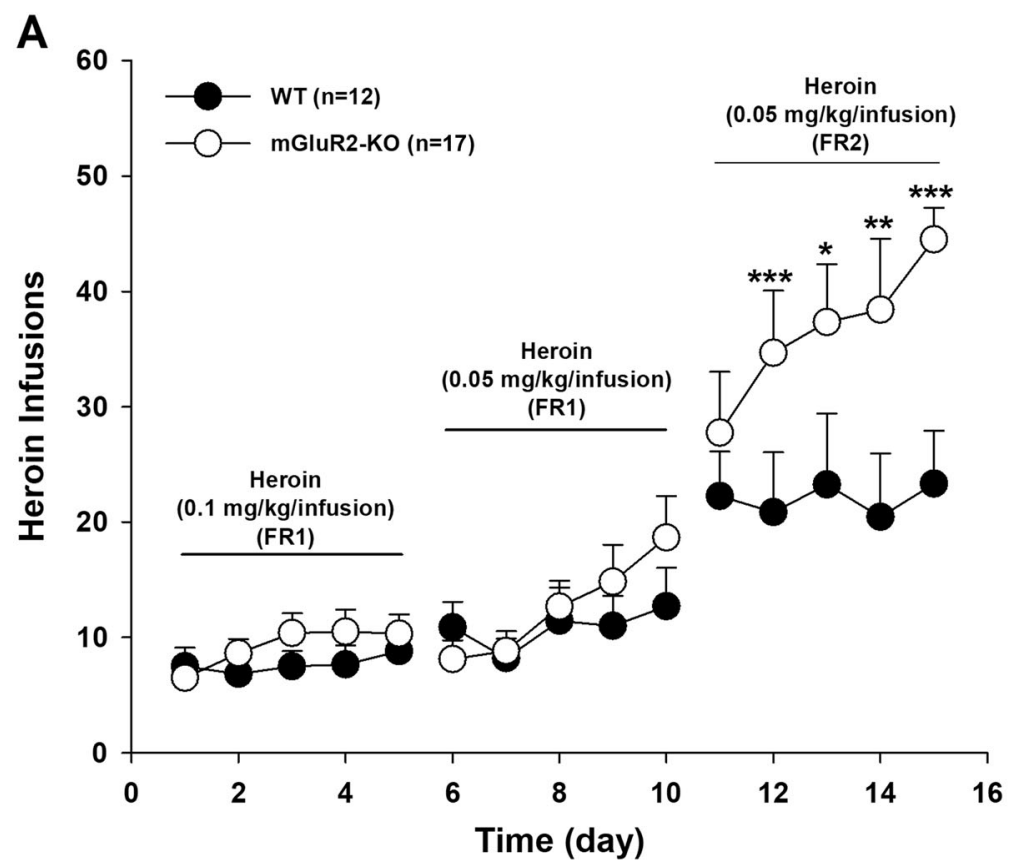

\section{B (WT - \#01)}
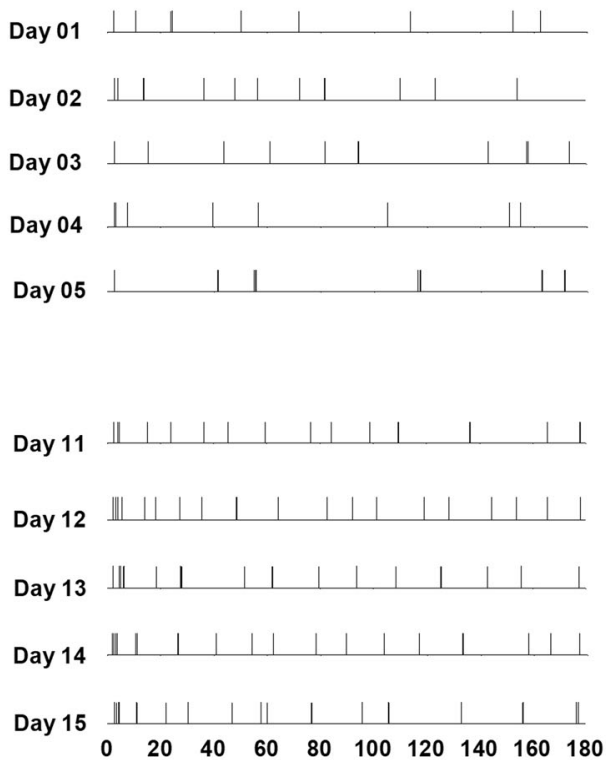

Time (min)
C (mGluR2-KO -\#01)

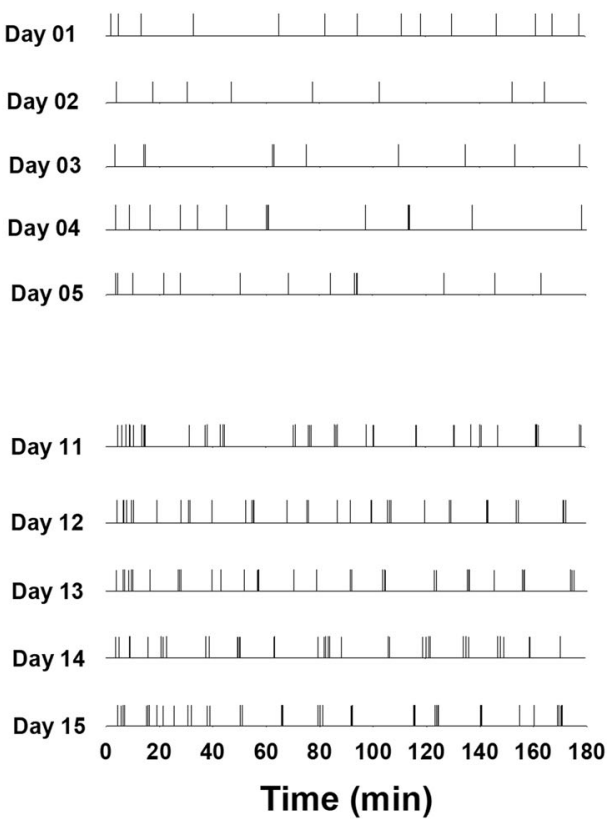

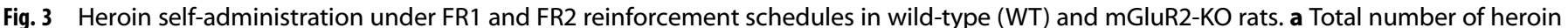

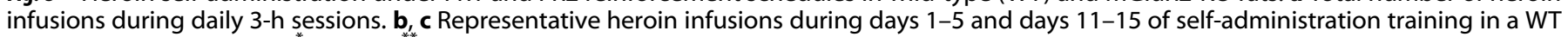
rat and a mGluR2-KO rat. ${ }^{*} p<0.05,{ }^{* *} p<0.01,{ }^{* * *} p<0.001$ compared to WT

affected by other factors such as the price for getting a reward [30]. Therefore, we further measured the effects of mGluR2 deletion on heroin self-administration under a PR schedule, in which the break-point indicates the value of the reward and/or the motivation for getting a reward in that subject [27]. Figure $4 \mathrm{c}$ shows that mGluR2 deletion significantly lowers the break-point for heroin self-administration compared to WT rats. Two-way ANOVA for repeated measures over heroin doses revealed a significant genotype main effect $\left(F_{1,20}=45.30, p<0.001\right)$, dose main effect $\left(F_{1}, 20=36.39, p<0.001\right)$, and genotype $\times$ dose interaction $\left(F_{1,20}=4.76, p<0.05\right)$.
mGluR2 deletion decreases propensity to relapse for heroinseeking behavior

Figure 5 shows the active and inactive lever responding during heroin self-administration, extinction and heroin-induced reinstatement of drug-seeking behavior in both genotypes of rats. Consistent with the results for heroin infusions (Fig. 3), mGluR2-KO rats made significantly more active lever responses during heroin self-administration (Fig. 5a, genotype, $F_{1}, 108=9.5, p<0.01$; time, $F_{4,108}=12.8, p<0.001$; interaction, $\left.F_{4,108}=2.9, p<0.05\right)$, an effect which was most apparent at the $0.05 \mathrm{mg} / \mathrm{kg} /$ infusion maintenance dose under the FR2 schedule. 


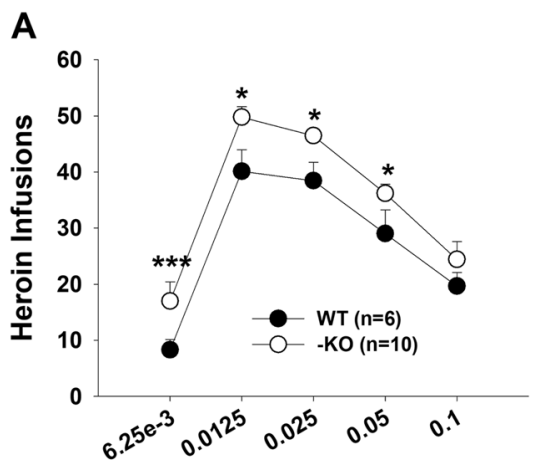

Heroin Dose (mg/kg/infusion)

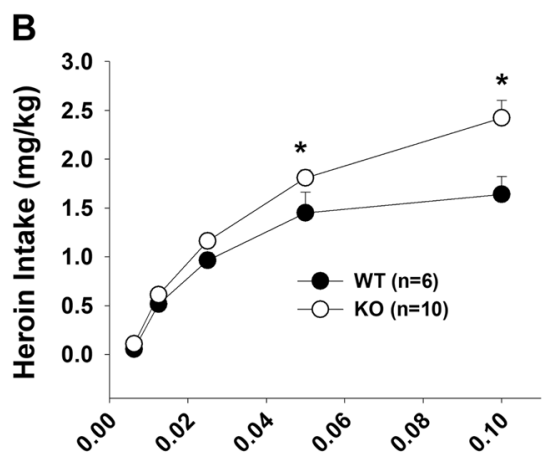

Heroin Dose (mg/kg/infusion)

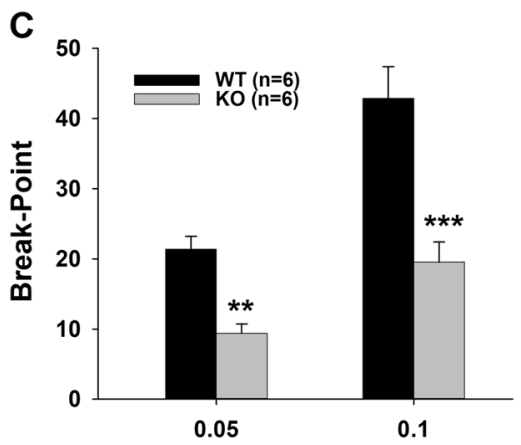

Heroin (mg/kg/infusion)

Fig. 4 Heroin self-administration dose-response functions and break-point levels for heroin self-administration under PR reinforcement schedule in wild-type (WT) and mGluR2-KO rats. a Heroin dose-response self-administration function illustrating the total numbers of heroin infusions across six doses during daily 3-hour sessions. b Cumulative heroin intake at each dose. c Break-point levels for heroin selfadministration under PR reinforcement schedule. ${ }^{*} p<0.05,{ }^{* *} p<0.01,{ }^{* * *} p<0.001$ compared to WT rats
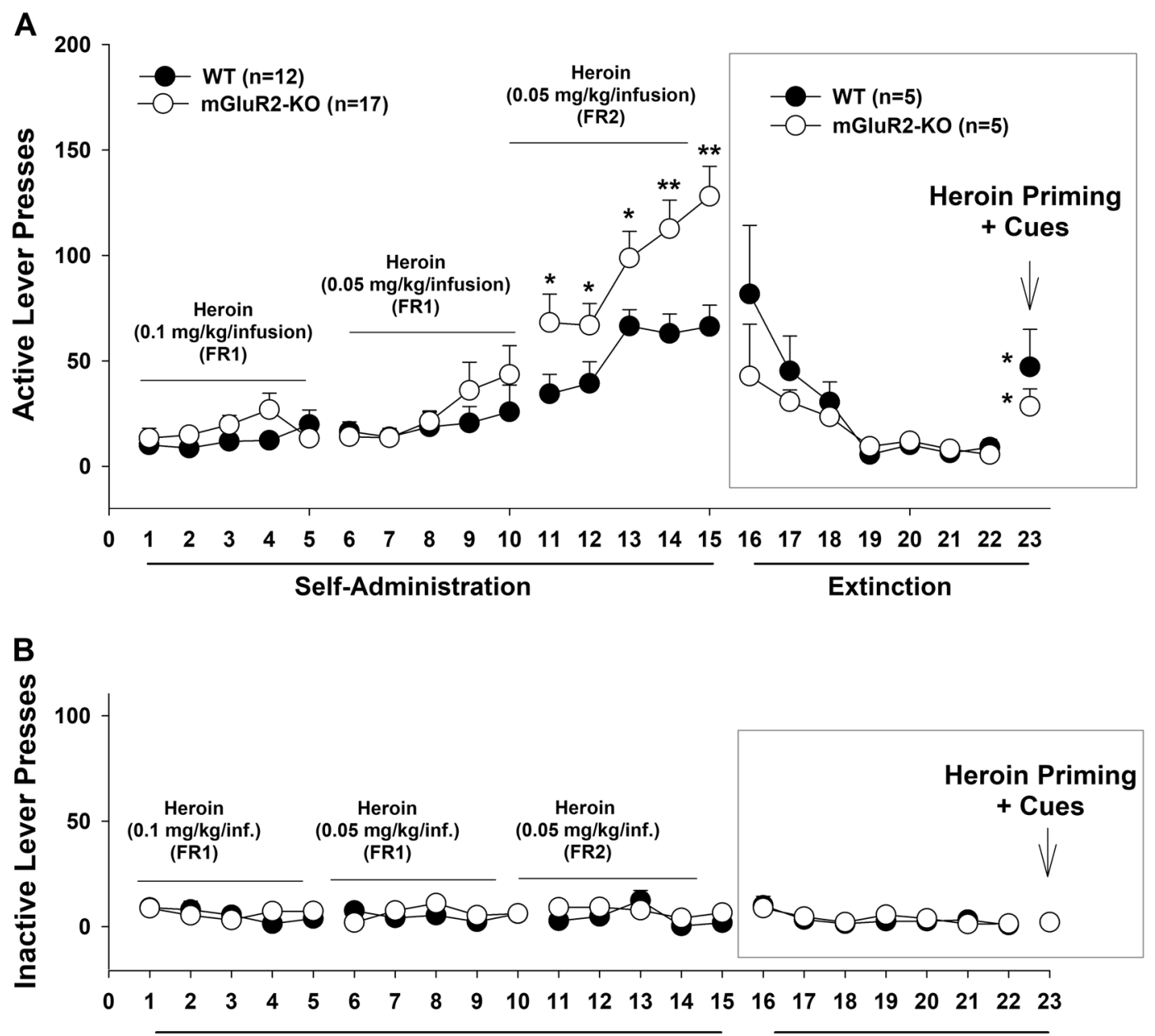

Self-Administration

Extinction

Fig. 5 Active (a) and inactive (b) lever responses during self-administration, extinction, and heroin-primed reinstatement in WT and mGluR2KO rats. ${ }^{*} p<0.05,{ }^{* *} p<0.01$ compared to WT rats

In contrast to findings in the heroin self-administration phase, mGluR2-KO rats responded less (i.e., showed faster extinction) on days 1 and 2 of extinction training, although this decrease was not statistically significant (Fig. $5 a, F_{1,8}=0.62, p>0.05$ ). After drugseeking behavior was extinguished, subsequent heroin priming plus cues induced significant reinstatement of drug seeking in both groups of rats compared with the last extinction session.
mGluR2-KO rats exhibited lower reinstatement responses to heroin priming plus cues compare to WT rats, although this decrease is not statistically significant (Fig. $5 \mathrm{~b}, t=1.17$, two-tailed $p>0.05$; one-tailed $p=0.055$ ). There were no significant differences in inactive lever responses between WT and mGluR2-KO rats during heroin self-administration (Fig. $5 b, F_{1,26}=2.88, p>0.05$ ) or extinction $\left(F_{1,26}=0.295, p>0.05\right)$. 
mGluR2 deletion enhances opioid analgesia, but does not alter opioid analgesic tolerance

We also evaluated the effects of morphine ( 3 and $10 \mathrm{mg} / \mathrm{kg}$, s.c.) on pain thresholds (latency to forepaw lick) in WT and mGluR2-KO rats (Fig. 6a, b). Morphine produced a dose-dependent increase in antinociception (Fig. 6a, b). However, there was no difference in latency to forepaw lick between the two genotypes of rats after the lower dose of morphine $(3 \mathrm{mg} / \mathrm{kg}$ ) administration (Fig. 6a, genotype main effect, $\left.F_{1,112}=0.27, p>0.05\right)$. In contrast, at a higher dose $(10 \mathrm{mg} / \mathrm{kg})$, morphine appeared to be more potent in attenuation of hot-plate pain reflex in mGluR2-KO rats than in WT rats, manifested as a significant increase in amplitude and duration of the analgesic effects of morphine (Fig. $6 \mathrm{~b}$, genotype, $F_{1,112}=1.2, p>0.05$; time, $F_{8,112}=5.3, p<0.001$; interaction, $F_{8}$, $112=1.2, p>0.05)$. Individual group comparisons revealed a significant increase in latency to forepaw lick in mGluR2-KO rats compared to that in WT rats at the 90 and 120 -min time points, suggesting higher sensitivity to morphine's analgesic effects following mGluR2 deletion.

We next determined whether mGluR2 deletion alters the development of opioid analgesic tolerance after repeated morphine administration. Figure $6 c$ shows that repeated administration of morphine produced rapid tolerance to opioid analgesia over time in both genotypes (time, $F_{10,140}=19.8, p<$ $0.001)$. However, there is no difference in tolerance development between the two groups of rats (genotype, $F_{1,140}=0.85, p>0.05$; interaction, $F_{10,140}=0.29, p>0.05$ ).

\section{mGluR2 deletion increases naloxone-precipitated withdrawal} symptoms

Lastly, we determined whether mGluR2 deletion alters somatic withdrawal signs precipitated by naloxone administration following extended exposure to daily morphine injections. We found that mGluR2-KO rats displayed higher levels of withdrawal symptoms than WT rats as assessed by diarrhea, wet-dog shakes, teeth chatter, digging, and ptosis symptoms, as well as the total number of withdrawal signs in two-tailed $t$ tests (Fig. $6 \mathrm{~d} ;(t(8)=$ $-7.01-4.29$, all $p<0.05)$ ).

\section{DISCUSSION}

In this study we sought to determine whether low-mGluR2 expression conveys increased vulnerability to opioid abuse by using a transgenic knockout rat model to evaluate multiple facets of opioid addiction. Our results indicate that, compared to WT controls, mGluR2-KO rats displayed higher NAc DA and locomotor responses to heroin and higher heroin intake during voluntary self-administration. In addition, mGluR2-KO rats also displayed enhanced morphine analgesia and naloxone-precipitated withdrawal symptoms. These findings suggest that mGluR2 may play an important role in mediating opioid action, such that deletion of this receptor leads to increased vulnerability to opioids and possibly potentiates the transition from occasional opioid use to abuse.

\section{mGluR2 deletion increases vulnerability to opioid reward}

The neural mechanisms underlying vulnerability to drugs of abuse remain unclear. Given the critical role of DA in multiple aspects of drug abuse and addiction, most prior studies have focused on the mesolimbic DA system [31]. For example, lower D2 or D3 receptor availability in the striatum has been considered a possible risk factor that may influence susceptibility to continued drug use and abuse $[28,32,33]$. By using transgenic mGluR2-KO rats in the present study, we found that genetic mutation in mGluR2 leads to loss of mGluR2 expression and a significant increase in heroin intake during self-administration, suggesting that low-mGluR2 expression may be an important risk factor for the initial development of opioid abuse and addiction. This finding is consistent with recent reports that mGluR2-KO mice consume more alcohol [34] and mGluR2-KO rats self-administer more cocaine [25] than WT controls.

It remains unknown how mGluR2 deletion increases heroin selfadministration and heroin intake. Given the important role of DA in opioid reward and addiction [8], we hypothesize that augmented DA responses to heroin may in part underlie the increased heroin self-administration observed in mGluR2-KO rats. Several lines of evidence support this hypothesis. First, in vivo microdialysis provides direct evidence supporting this hypothesis. Second, mGluR2-KO rats displayed augmented locomotor responses to repeated heroin exposure. Since locomotor activity is largely DA-dependent [35], the enhanced locomotor sensitization to heroin may be the result of increased DA responses. Third, mGluR2-KO rats displayed higher baseline levels of extracellular DA and glutamate in the NAC compared to WT rats, which is consistent with our previous findings using no-net flux microdialysis techniques [25]. This increase in basal extracellular glutamate may increase NAc neuron excitability via activation of glutamate receptors, thereby increasing sensitivity to heroin. The present finding on basal levels of extracellular DA and glutamate is also consistent with prior reports that activation of mGluR $_{2 / 3}$ by LY379268 inhibited DA and glutamate in the NAc shell $[14,25]$.

Classically, enhanced locomotor sensitization and vertical shifts in drug dose-response functions are interpreted as increased sensitivity to drug reward and consequently an addiction-" vulnerable" phenotype $[36,37]$. Because the magnitude of DA elevation in the NAc correlates with sensitivity to a drug of abuse [38], we propose that mGluR2-KO rats may be more sensitive to opioid reinforcement and potentially more likely to transition to stable, addiction-like patterns of use. This interpretation is further supported by our finding that mGluR2-KO rats experienced greater morphine-induced analgesia and elevated somatic withdrawal symptoms, the latter of which are major deterrents to treatment efforts for opioid use disorder [6]. However, this hypothesis does not appear to be supported by the finding that mGluR2 deletion significantly decreased PR break-point for heroin self-administration, which is often interpreted as a reduction in drug reinforcing strength [39]. Conversely, decreased break-point may also be interpreted as a reduction in motivation for drug seeking [39], suggesting that the utility of PR break-point in evaluating drug reward vs. motivation for drug seeking may be limited. The latter interpretation is consistent with the finding that mGluR2-KO rats also displayed lower propensity for heroin seeking as observed during heroin extinction and reinstatement testing.

\section{Different mechanisms underlying enhanced vulnerability to} cocaine in mGluR2-KO rats

We note that the above findings are different and even opposite to our previous report that mGluR2 deletion did not significantly alter the magnitude of cocaine-enhanced extracellular DA and glutamate [25]. Rather, when normalized to elevated basal levels of extracellular DA and glutamate, mGluR2-KO rats displayed a reduction in NAC DA and glutamate responses to cocaine. Since mGluR2 deletion also decreased PR break-point for cocaine selfadministration and reduced cocaine-enhanced brain-stimulation reward and relapse [25], we interpreted increased cocaine selfadministration and cocaine intake as a compensatory response to reduced cocaine reward after mGluR2 deletion [25]. Whatever the mechanisms underlying different vulnerabilities to heroin versus cocaine in mGluR2-KO rats, these diverging findings highlight the importance of evaluating risk factors for multiple drugs of abuse.

Molecular mechanisms underlying enhanced DA/glutamate response to heroin in mGluR2-KO rats

How does mGluR2 deletion increase baseline levels of extracellular DA and glutamate in the NAc? Evidence has shown that mGluR2 is expressed in glutamate terminals [40] and functionally acts as a 

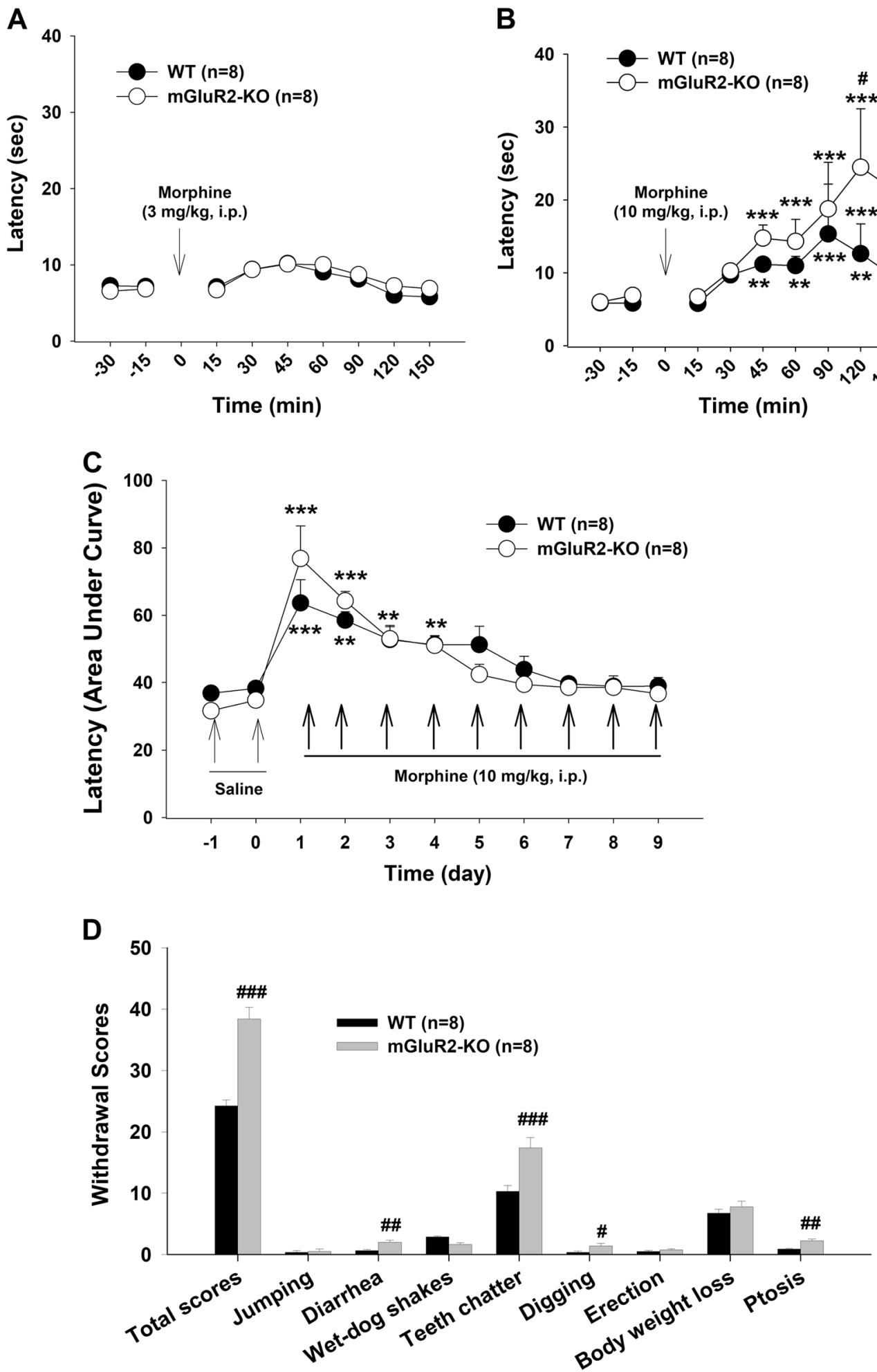

Fig. 6 Morphine-induced analgesia, analgesic tolerance, and naloxone-precipitated withdrawal signs in WT and mGluR2-KO rats. a Time courses of $3 \mathrm{mg} / \mathrm{kg}$ morphine-induced analgesia as assessed by latency to forepaw lick on the hot-plate test. $\mathbf{b}$ Time courses of $10 \mathrm{mg} / \mathrm{kg}$ morphine-induced analgesia in both genotypes of rats, illustrating an enhanced and prolonged analgesic response in mGluR2-KO compared to WT rats. c Evaluation of morphine tolerance in analgesia following repeated injections of morphine (10 mg/kg, i.p., for 9 days) over time. d Naloxone-precipitated withdrawal symptoms in repeated morphine-treated rats measured at $3 \mathrm{~h}$ after the last morphine injection. ${ }^{*} p<0.05$, ${ }^{* *} p<0.01,{ }^{* * * *} p<0.001$ compared to the baseline before morphine injection. ${ }^{\#} p<0.05,{ }^{\# \#} p<0.01,{ }^{\# \# \#} p<0.001$ compared to WT 
glutamate autoreceptor negatively modulating glutamate release $[11,13]$. Accordingly, mGluR2 deletion causes disinhibition (increases) in basal glutamate release. While there is little evidence demonstrating that mGluR2 is expressed on DA neurons or their terminals, a handful of studies have recently reported that a subpopulation ( $30 \%)$ of midbrain DA neurons corelease DA and glutamate $[41,42]$. Thus, one possibility is that mGluR2 may be expressed in a dual DA-glutamate neuronal phenotype, and therefore, mGluR2 deletion causes an increase in both DA and glutamate via a disinhibition mechanism. Another possibility is that enhanced extracellular glutamate in mGluR2-KO rats may stimulate basal DA release by activation of glutamate receptors on VTA DA neurons or their terminals in the striatum.

In addition to the mechanism by which basal DA and glutamate are elevated, it remains unclear how mGluR2 deletion altered NAc DA and glutamate responses to heroin as observed in the present study. One possibility is that mGluR2 deletion may upregulate muopioid receptor expression in the brain, particularly in VTA GABAergic neurons, thereby causing enhanced DA release after re-exposure to heroin via a GABAergic disinhibition mechanism. Similarly, mu-opioid receptor upregulation may also occur in GABAergic neurons in other brain regions such as prefrontal cortex and hippocampus where high densities of glutamatergic neurons project to the NAc. Thus, activation of mu-opioid receptors on GABAergic neurons in these brain regions may disinhibit glutamatergic neurons, enhancing glutamate release in the NAc after re-exposure to heroin in mGluR2-KO rats. This hypothesis may not only explain why mGluR2 deletion caused enhanced NAC DA and glutamate responses to heroin, but may also explain why mGluR2 deletion did not significantly alter the amplitude of cocaine-enhanced extracellular DA and glutamate.

\section{mGluR2 involvement in relapse to opioid vs. cocaine seeking}

Another important finding in the present study is that mGluR2-KO rats showed a tendency toward reduced heroin seeking during extinction and reinstatement compared to WT rats. This finding is slightly different from our previous report that mGluR2 deletion caused a significant reduction in cocaine- and cue-induced reinstatement of cocaine seeking [25]. This may be related to a smaller sample size (five animals/group) and a single dose (1 mg/ $\mathrm{kg}$ ) of heroin priming used in this test. In addition, it is well documented that heroin-induced reinstatement of drug-seeking behavior is positively correlated to increases in NAC DA and glutamate responses to heroin [43-45]. Drug craving and relapse is also associated with reductions in basal extracellular DA and glutamate in the NAc after chronic cocaine or opioid administration [10, 46-48]. Accordingly, the increased glutamate/DA responses to heroin observed in mGluR2-KO rats should produce an enhanced reinstatement response to heroin, while higher basal levels of extracellular DA and glutamate observed in mGluR2-KO rats should produce a reduction in relapse to heroin seeking by normalization of reduced DA and glutamate tone. Thus, the nonsignificant reduction in heroin seeking observed in mGluR2$\mathrm{KO}$ rats might be a result of these opposing actions. In contrast to increased DA/glutamate responses to heroin, mGluR2 deletion caused a significant reduction in NAc DA/glutamate responses to cocaine, which may well explain why mGluR2 deletion produced a more potent reduction in relapse to cocaine seeking [25].

mGluR2 involvement in opioid analgesia and tolerance In addition to drug reward, DA is also involved in antinociception. DA has an antinociceptive effect via activation of DA receptors in brain regions involved in pain modulation and transmission [49, 50], and DA receptor antagonists attenuate opioid analgesia [51]. Enhanced DA responses to heroin in mGluR2-KO rats may underlie enhanced morphine analgesia observed in the present study.
However, mGluR2 deletion did not significantly alter opioid analgesic tolerance as measured by hot-plate test. The molecular mechanisms underlying opioid tolerance are not fully understood. A well-accepted view is that opioid tolerance is associated with opioid receptor phosphorylation, desensitization, and endocytosis [52-54]. Since mGluR2 deletion produced enhanced opioid analgesia, it is unlikely that mGluR2 regulates mu-opioid receptor internalization processes that lead to tolerance to opioid analgesia. However, a limitation of the present study is that only thermal nociceptive responses were compared between WT and mGluR2-KO mice. It is possible that analgesic tolerance was not detectable using the current hot-plate test, whereas other approaches (such as mechanical or chemical stimuli) may be able to reveal genotypic differences. In addition, we used a single morphine dose regimen ( $10 \mathrm{mg} / \mathrm{kg} \times 9$ days) in this study. It is possible that mGluR2 deletion alters the development of opioid tolerance in analgesia to higher doses of morphine $(3,10,20,30,60$, $100 \mathrm{mg} / \mathrm{kg}$ ) that are also commonly used in studying opioid tolerance $[22,55]$. Finally, the mGluR2-KO rats used in the present studies are constitutive mGluR2-knockouts. Thus, it is possible that compensatory neuroadaptive responses occurred in mGluR2-KO rats in early development that compromise mGluR2 loss-induced changes in analgesic tolerance. More studies are required to further address this issue.

mGluR2 involvement in opioid withdrawal syndromes Lastly, we found that mGluR2 deletion led to enhanced naloxoneprecipitated withdrawal responses. Prior reports indicate that acute administration of high doses of morphine $(10 \mathrm{mg} / \mathrm{kg})$ significantly inhibit glutamate release in the NAc and other brain regions [56, 57], Moreover, glutamate and its receptors are critically involved in withdrawal-associated increases in neuronal activity of the locus coeruleus (LC) and the expression of opioid withdrawal signs [58]. During withdrawal, glutamate levels in the VTA and NAC are elevated, and mGluR2/3 function is enhanced $[6,56,57,59]$. Activation of mGluR2 significantly attenuates morphine withdrawal-elevated NAc glutamate [46, 47]. In the present study, we found that basal levels of extracellular glutamate were increased in the NAc. This action may also occur in other brain regions such as the LC via a mGluR2 disinhibition mechanism. These findings suggest that elevated glutamatergic tone in the LC may underlie increased naloxone-precipitated opioid withdrawal signs in mGluR2-KO rats. It is also likely that mGluR2 deletion may significantly alter downstream intracellular processes that mediate expression of withdrawal symptoms. Moreover, increased drug self-administration observed in mGluR2-KO rats may be driven partially by negative reinforcement mechanisms, such as avoidance of withdrawal symptoms.

In conclusion, the present findings suggest that low-mGluR2 expression may represent a risk factor for opioid abuse, by conveying increased sensitivity to opioid reward and potentiating opioid analgesia and withdrawal symptoms. We propose these effects are mediated through the loss of mGluR2 on presynaptic glutamate terminals in the NAC and other brain regions, which subsequently caused an increase in both basal extracellular NAc glutamate and DA and DA/glutamate responses to heroin. LowmGluR2 availability in the brain may therefore represent a useful biomarker for opioid addiction risk. Recent progress in developing positron emission tomography ligands to evaluate mGluR2 receptor binding [60-62] will provide opportunities for identifying individuals vulnerable to opioid abuse and for preventative interventions and treatment options for those at highest risk.

\section{FUNDING}

This research was supported by the Intramural Research Program (IRP) of the National Institute on Drug Abuse (NIDA) (Z1A DA000478), National Institutes of Health (NIH). 


\section{AUTHOR CONTRIBUTIONS}

J.T.G., C.J.J., E.G., and Z.-X. X. designed the experiments. J.T.G., H.J.Y., G.H.B., and Y.H. performed the experiments. J.T.G., C.J.J., and Z.X.X. analyzed the data and prepared the figures. C.J.J. and Z.-X. X. wrote the manuscript.

\section{ADDITIONAL INFORMATION}

Competing interests: The authors declare no competing interests.

Publisher's note: Springer Nature remains neutral with regard to jurisdictional claims in published maps and institutional affiliations.

\section{REFERENCES}

1. World Health Organization. Management of substance abuse: Opiates. 2018 http://www.who.int/substance_abuse/facts/opiates/en/. Accessed 15 August 2018.

2. Department of Health and Human Services. About the U.S. Opioid Epidemic. 2018. https://www.hhs.gov/opioids/about-the-epidemic/. Accessed 15 August 2018.

3. American Psychiatric Association. Diagnostic and statistical manual of mental disorders. 5th ed. Arlington, VA: American Psychiatric Publishing; 2013.

4. American Society of Addiction Medicine. Opioid Addiction 2016 Facts \& Figures. 2016. https://www.asam.org/docs/default-source/advocacy/opioid-addictiondisease-facts-figures.pdf. Accesssed 15 August 2018.

5. Jordan CJ, Andersen SL. Sensitive periods of substance abuse: early risk for the transition to dependence. Dev Cog Neurosci. 2017;25:29-44.

6. Chartoff EH, Connery HS. It's MORe exciting than mu: crosstalk between mu opioid receptors and glutamatergic transmission in the mesolimbic dopamine system. Front Pharmacol. 2014;5:116.

7. Fields HL, Margolis EB. Understanding opioid reward. Trends Neurosci. 2015;38 (4):217-25.

8. Wise RA. Dopamine and reward: the anhedonia hypothesis 30 years on. Neurotox Res. 2008;14(2-3):169-83.

9. Swendsen J, Le Moal M. Individual vulnerability to addiction. Ann NY Acad Sci. 2011;1216:73-85.

10. Kalivas PW. The glutamate homeostasis hypothesis of addiction. Nat Rev Neurosci. 2009;10(8):561-72

11. Moussawi K, Kalivas PW. Group II metabotropic glutamate receptors (mGlu2/3) in drug addiction. Eur J Pharmacol. 2010;639(1-3):115-22.

12. Pomierny-Chamiolo L, Miszkiel J, Frankowska M, Pomierny B, Niedzielska E, Smaga I, et al. Withdrawal from cocaine self-administration and yoked cocaine delivery dysregulates glutamatergic mGlu5 and NMDA receptors in the rat brain. Neurotox Res. 2015;27(3):246-58.

13. Caprioli D, Justinova Z, Venniro $M$, Shaham Y. Effect of novel allosteric modulators of metabotropic glutamate receptors on drug self-administration and relapse: a review of preclinical studies and their clinical implications. Biol Psychiatry. 2018;84:180-92.

14. Greenslade RG, Mitchell SN. Selective action of (-)-2-oxa-4-aminobicyclo[3.1.0] hexane-4,6-dicarboxylate (LY379268), a group II metabotropic glutamate receptor agonist, on basal and phencyclidine-induced dopamine release in the nucleus accumbens shell. Neuropharmacology . 2004;47(1):1-8.

15. Bossert JM, Busch RF, Gray SM. The novel mGluR2/3 agonist LY379268 attenuates cue-induced reinstatement of heroin seeking. Neuroreport . 2005;16(9):1013-6.

16. Baharlouei N, Sarihi A, Komaki A, Shahidi S, Haghparast A. Blockage of acquisition and expression of morphine-induced conditioned place preference in rats due to activation of glutamate receptors type II/III in nucleus accumbens. Pharmacol Biochem Behav. 2015;135:192-8.

17. Baharlouei N, Sarihi A, Moradi M, Zarrabian S, Haghparast A. Microinjection of the mGluR2/3 agonist, LY379268, into the nucleus accumbens attenuates extinction latencies and the reinstatement of morphine-induced conditioned place preference in rats. Behav Pharmacol. 2018.

18. Bossert JM, Gray SM, Lu L, Shaham Y. Activation of group II metabotropic glutamate receptors in the nucleus accumbens shell attenuates context-induced relapse to heroin seeking. Neuropsychopharmacology . 2006;31(10):2197-209.

19. Bossert JM, Liu SY, Lu L, Shaham Y. A role of ventral tegmental area glutamate in contextual cue-induced relapse to heroin seeking. J Neurosci. 2004;24 (47):10726-30.

20. Chiechio S. Modulation of chronic pain by metabotropic glutamate receptors. Adv Pharmacol. 2016;75:63-89.

21. Zammataro M, Chiechio S, Montana MC, Traficante A, Copani A, Nicoletti F, et al. mGlu2 metabotropic glutamate receptors restrain inflammatory pain and mediate the analgesic activity of dual $\mathrm{mGlu2/mGlu3}$ receptor agonists. Mol Pain. 2011;7:6.
22. Osikowicz M, Mika J, Makuch W, Przewlocka B. Glutamate receptor ligands attenuate allodynia and hyperalgesia and potentiate morphine effects in a mouse model of neuropathic pain. Pain . 2008;139(1):117-26.

23. Wu X, Shi M, Wei C, Yang M, Liu Y, Liu Z, et al. Potentiation of synaptic strength and intrinsic excitability in the nucleus accumbens after 10 days of morphine withdrawal. J Neurosci Res. 2012;90(6):1270-83.

24. Rasmussen K, Hsu MA, Vandergriff J. The selective mGlu2/3 receptor antagonist LY341495 exacerbates behavioral signs of morphine withdrawal and morphinewithdrawal-induced activation of locus coeruleus neurons. Neuropharmacology. 2004;46(5):620-8.

25. Yang HJ, Zhang HY, Bi GH, He Y, Gao JT, Xi ZX. Deletion of type 2 metabotropic glutamate receptor decreases sensitivity to cocaine reward in rats. Cell Rep. 2017;20(2):319-32.

26. Xi ZX, Peng XQ, Li X, Song R, Zhang HY, Liu QR, et al. Brain cannabinoid $C B(2)$ receptors modulate cocaine's actions in mice. Nat Neurosci. 2011;14(9):1160-6.

27. Richardson NR, Roberts DC. Progressive ratio schedules in drug selfadministration studies in rats: a method to evaluate reinforcing efficacy. J Neurosci Methods. 1996;66(1):1-11.

28. Zhan J, Jordan CJ, Bi GH, He XH, Gardner EL, Wang YL et al. Neuropharmacology genetic deletion of the dopamine D3 receptor increases vulnerability to heroin in mice. Neuropharmacology. 2018;141:11-20.

29. Gellert VF, Holtzman SG. Development and maintenance of morphine tolerance and dependence in the rat by scheduled access to morphine drinking solutions. J Pharmacol Exp Ther. 1978;205(3):536-46.

30. Lynch WJ, Carroll ME. Regulation of drug intake. Exp Clin Psychopharmacology 2001;9(2):131-143.

31. Volkow ND, Fowler JS, Wang GJ, Baler R, Telang F. Imaging dopamine's role in drug abuse and addiction. Neuropharmacology. 2009;56:3-8.

32. Song R, Zhang HY, Li X, Bi GH, Gardner EL, Xi ZX. Increased vulnerability to cocaine in mice lacking dopamine D3 receptors. Proc Natl Acad Sci USA. 2012;109 (43):17675-80.

33. Volkow ND, Fowler JS, Wang GJ. Role of dopamine in drug reinforcement and addiction in humans: results from imaging studies. Behav Pharmacol. 2002;13 (5-6):355-66.

34. Zhou Z, Karlsson C, Liang T, Xiong W, Kimura M, Tapocik JD, et al. Loss of metabotropic glutamate receptor 2 escalates alcohol consumption. Proc Natl Acad Sci USA. 2013;110(42):16963-8.

35. Li X, Hoffman AF, Peng XQ, Lupica CR, Gardner EL, Xi ZX. Attenuation of basal and cocaine-enhanced locomotion and nucleus accumbens dopamine in cannabinoid CB1-receptor-knockout mice. Psychopharmacology. 2009;204(1):1-11.

36. Piazza PV, Deminiere JM, le Moal M, Simon H. Stress- and pharmacologically induced behavioral sensitization increases vulnerability to acquisition of amphetamine self-administration. Brain Res. 1990;514(1):22-6.

37. Piazza PV, Deroche-Gamonent V, Rouge-Pont F, Le Moal M. Vertical shifts in selfadministration dose-response functions predict a drug-vulnerable phenotype predisposed to addiction. J Neurosci. 2000;20(11):4226-32.

38. Volkow ND, Wang GJ, Fowler JS, Tomasi D, Telang F, Baler R. Addiction: decreased reward sensitivity and increased expectation sensitivity conspire to overwhelm the brain's control circuit. Bioessays. 2010;32(9):748-55.

39. Ward SJ, Morgan D, Roberts DC. Comparison of the reinforcing effects of cocaine and cocaine/heroin combinations under progressive ratio and choice schedules in rats. Neuropsychopharmacology. 2005;30(2):286-95.

40. Testa CM, Friberg IK, Weiss SW, Standaert DG. Immunohistochemical localization of metabotropic glutamate receptors mGluR1a and mGluR2/3 in the rat basal ganglia. J Comp Neurol. 1998;390(1):5-19.

41. Berube-Carriere N, Riad M, Dal Bo G, Levesque D, Trudeau LE, Descarries L. The dual dopamine-glutamate phenotype of growing mesencephalic neurons regresses in mature rat brain. J Comp Neurol. 2009;517(6):873-91.

42. Yamaguchi T, Qi J, Wang HL, Zhang S, Morales M. Glutamatergic and dopaminergic neurons in the mouse ventral tegmental area. Eur J Neurosci. 2015;41 (6):760-72.

43. LaLumiere RT, Kalivas PW. Glutamate release in the nucleus accumbens core is necessary for heroin seeking. J Neurosci. 2008;28(12):3170-7.

44. Shen HW, Scofield MD, Boger $H$, Hensley M, Kalivas PW. Synaptic glutamate spillover due to impaired glutamate uptake mediates heroin relapse. J Neurosci. 2014;34(16):5649-57.

45. Knackstedt LA, Kalivas PW. Glutamate and reinstatement. Curr Opin Pharmacol. 2009;1:59-64

46. Diana M, Muntoni AL, Pistis M, Melis M, Gessa GL. Lasting reduction in mesolimbic dopamine neuronal activity after morphine withdrawal. Eur J Neurosci. 1999;11(3):1037-41.

47. Sun L, Hu L, Li Y, Cui C. Mesoaccumbens dopamine signaling alteration underlies behavioral transition from tolerance to sensitization to morphine rewarding properties during morphine withdrawal. Brain Struct Funct. 2014;219(5):1755-71. 
48. Qi J, Zhang S, Wang HL, Barker DJ, Miranda-Barrientos J, Morales M. VTA glutamatergic inputs to nucleus accumbens drive aversion by acting on GABAergic interneurons. Nat Neurosci. 2016;19(5):725-33.

49. Meyer PJ, Morgan MM, Kozell LB, Ingram SL. Contribution of dopamine receptors to periaqueductal gray-mediated antinociception. Psychopharmacology. 2009;204(3):531-40.

50. Magnusson JE, Fisher K. The involvement of dopamine in nociception: the role of $D(1)$ and D(2) receptors in the dorsolateral striatum. Brain Res. 2000;855(2):260-6.

51. Altier N, Stewart J. Dopamine receptor antagonists in the nucleus accumbens attenuate analgesia induced by ventral tegmental area substance $\mathrm{P}$ or morphine and by nucleus accumbens amphetamine. J Pharmacol Exp Ther. 1998;285 (1):208-15.

52. Koch T, Hollt V. Role of receptor internalization in opioid tolerance and dependence. Pharmacol Ther. 2008;117(2):199-206.

53. Williams JT, Ingram SL, Henderson G, Chavkin C, von Zastrow M, Schulz S, et al. Regulation of mu-opioid receptors: desensitization, phosphorylation, internalization, and tolerance. Pharmacol Rev. 2013;65(1):223-54.

54. Yu G, Zhang FQ, Tang SE, Lai MJ, Su RB, Gong ZH. Continuous infusion versus intermittent bolus dosing of morphine: a comparison of analgesia, tolerance, and subsequent voluntary morphine intake. J Psychiatr Res. 2014;59:161-6.

55. Wang XF, Barbier E, Chiu YT, He Y, Zhan J, Bi GH, Zhang HY, Feng B, Liu-Chen LY, Wang JB, Xi ZX. T394A mutation at the $\mu$ opioid receptor blocks opioid tolerance and increases vulnerability to heroin self-administration in mice. J Neurosci. 2016;36:10392-403.

56. Sepulveda MJ, Hernandez L, Rada P, Tucci S, Contreras E. Effect of precipitated withdrawal on extracellular glutamate and aspartate in the nucleus accumbens of chronically morphine-treated rats: an in vivo microdialysis study. Pharmacol Biochem Behav. 1998;60(1):255-62.

57. Sepulveda J, Oliva P, Contreras E. Neurochemical changes of the extracellular concentrations of glutamate and aspartate in the nucleus accumbens of rats after chronic administration of morphine. Eur J Pharmacol. 2004;483(2-3):249-58.

58. Zhu H, Rockhold RW, Ho IK. The role of glutamate in physical dependence on opioids. Jpn J Pharmacol. 1998;76(1):1-14.

59. Robbe D, Bockaert J, Manzoni OJ. Metabotropic glutamate receptor 2/3-dependent long-term depression in the nucleus accumbens is blocked in morphine withdrawn mice. Eur J Neurosci. 2002;16(11):2231-5.

60. Spanagel R. Animal models of addiction. Dialogues Clin Neurosci. 2017;19 (3):247-58.

61. Andres Jl, Alcazar J, Cid JM, De Angelis M, Iturrino L, Langlois X, et al. Synthesis, evaluation, and radiolabeling of new potent positive allosteric modulators of the metabotropic glutamate receptor 2 as potential tracers for positron emission tomography imaging. J Med Chem. 2012;55(20):8685-99.

62. Lohith T, McQuade P, Salinas C, Anderson M, Reynders T, Bautmans A et al. Firstin-human PET imaging of mGluR2 receptors. J Nucl Med. 2016;57:213. 